\title{
On-farm methane measurements during milking correlate with total methane production by individual dairy cows
}

\author{
P. C. Garnsworthy, ${ }^{1}$ J. Craigon, J. H. Hernandez-Medrano, and N. Saunders \\ The University of Nottingham, School of Biosciences, Sutton Bonington Campus, Loughborough LE12 5RD, UK
}

\begin{abstract}
The objective of this study was to investigate whether measurement of methane emissions by individual dairy cows during milking could provide a useful technique for monitoring on-farm methane emissions. To quantify methane emissions from individual cows on farm, we developed a novel technique based on sampling air released by eructation during milking. Eructation frequency and methane released per eructation were used to estimate methane emission rate. For 82 cows, methane emission rate during milking increased with daily milk yield $(\mathrm{r}=0.71)$, but varied between individuals with the same milk yield and fed the same diet. For 12 cows, methane emission rate recorded during milking on farm showed a linear relationship $\left(\mathrm{R}^{2}=0.79\right)$ with daily methane output by the same cows when housed subsequently in respiration chambers. For 42 cows, the methane emission rate during milking was greater on a feeding regimen designed to produce high methane emissions, and the increase compared with a control regimen was similar to that observed for cows in respiration chambers. It was concluded that, with further validation, on-farm monitoring of methane emission rate during milking could provide a low-cost reliable method to estimate daily methane output by individual dairy cows, which could be used to study variation in methane, to identify cows with low emissions, and to test outcomes of mitigation strategies.
\end{abstract}

Key words: methane, dairy cow, environmental impact, greenhouse gas inventory

\section{INTRODUCTION}

Methane is a greenhouse gas with a global warming potential 25 times that of $\mathrm{CO}_{2}$ (Forster et al., 2007). In ruminant animals, typically $80 \%$ of methane is generated in the rumen during microbial fermentation of cellulosic feed materials (enteric methane) and $20 \%$ by

Received June 6, 2011.

Accepted February 12, 2012.

${ }^{1}$ Corresponding author: Phil.Garnsworthy@nottingham.ac.uk decomposition of manure (Vergé et al., 2007), although these proportions will vary in dairy systems, with enteric methane ranging from 60 to $100 \%$ and manure ranging from 0 to $40 \%$, depending on diet composition and digestibility, animal housing, and manure storage and application systems (Rotz et al., 2010). Globally, the dairy sector is estimated to contribute $4 \%( \pm 26 \%)$ of anthropogenic greenhouse gas emissions (FAO, 2010). Methane accounts for $>50 \%$ of greenhouse gas emissions from milk production and its contribution can be up to $80 \%$ in grassland systems (FAO, 2010).

Under the terms of the 1997 Kyoto protocol, Annex I signatory nations are required to submit an annual national inventory of greenhouse gas emissions and to decrease total emissions by $5.2 \%$ of 1990 values before 2012. Some countries have introduced legislation with more stringent targets; the UK Climate Change Act 2008, for example, requires a decrease in greenhouse gas emissions by $80 \%$ of 1990 values before 2050 .

National methane inventories are calculated using 1 of 3 methodologies prescribed by the Intergovernmental Panel on Climate Change (IPCC, 2006). Each methodology entails calculating the national population of animals according to species (e.g., sheep, pigs, and cattle) or subgroup (e.g., total dairy cows or grazing cows and feedlot cows) and multiplying by appropriate emission factors. For dairy cows, tier 1 methodology uses a fixed emission factor per cow ranging from 128 $\mathrm{kg} / \mathrm{yr}$ in North America to $46 \mathrm{~kg} / \mathrm{yr}$ in Africa and the Middle East; tier 2 methodology uses a factor of 6.5 $\pm 1 \%$ of gross energy intake per cow; tier 3 methodology uses country-specific estimates of emissions factors derived from models that allow for parameters such as diet composition, seasonal variation, and possible mitigation strategies (IPCC, 2006).

Whichever methodology is used in their calculation, total methane emissions at farm or national level are the product of number of cows and emissions per cow. It is easy to count cows, but it is difficult to measure emissions by individual cows accurately on farms using conventional methods. This presents a problem for evaluating potential mitigation strategies and assessing their efficacy; methane emissions will always remain theoretical extrapolations from research findings unless 
a technique is developed to measure actual emissions under commercial conditions.

The reference method used for research purposes is the respiration chamber, in which an individual cow is confined for several days and methane emissions are calculated from gas flow and changes in gas composition between ventilation inlet and outlet ports (Grainger et al., 2007; Yan et al., 2010). Respiration chambers are accurate, but confinement distorts cow feeding behavior, and measurements take several days per cow. Enclosing grazing or penned animals in polytunnels has less effect on feeding behavior, but the polytunnel technique underpredicts methane emissions, is susceptible to temperature fluctuations, and is not suitable for large ruminants (Lockyer, 1997; Murray et al., 1999). Methane sensors around groups of cows are noninvasive and can be applied to commercial conditions, but measurements are compromised by variable wind and weather outdoors (Laubach and Kelliher, 2005; Griffith et al., 2008), and require specialist ventilation control indoors to avoid compromising cow health (Kinsman et al., 1995; Tremblay and Massé, 2008). Furthermore, group measurements limit experimental power and interpretation through lack of replication at the individual cow level. The sulfur hexafluoride $\left(\mathrm{SF}_{6}\right)$ tracer technique (Johnson et al., 1994) generates values for daily methane emissions by individual cows that correlate with chamber measurements (Grainger et al., 2007), but the technique requires frequent cow handling, insertion of a rumen bolus, and gas collection equipment attached to the animal's head that can interfere with normal behavior.

Given the limitations of available techniques for application under commercial conditions, the main objective of the current study was to investigate whether a novel technique involving measurement of methane concentrations in air expelled through eructation by cows during milking could provide useful information about total daily emissions by individual dairy cows on farm. Because dairy cows are milked up to 3 times daily in standard milking parlors and up to 6 times daily in automatic milking systems, milking provides an ideal opportunity to make repeated noninvasive recordings of individual methane emissions. Initial observations made using a hand-held methane analyzer showed large increases in methane concentration of exhaled air at approximately 1-min intervals during milking, which corresponded to when cows released gas from the rumen by eructation. We hypothesized that variations in eructation frequency and methane concentration in eructations are related to differences in daily emissions.

The second objective of the study was to compare measurements of methane measured online during milking with daily methane output measured in respiration chambers. This would provide an indication of the reliability of the technique.

The third objective of the study was to compare measurements of methane measured online during milking in cows under feeding regimens designed to generate different levels of methane emissions. This would indicate whether the technique was sensitive enough to detect differences in methane emissions caused by dietary changes.

\section{MATERIALS AND METHODS}

Animal work was conducted under authority of the UK Animal (Scientific Procedures) Act 1986, and approval was obtained from the University of Nottingham animal ethics committee before commencement of the study.

\section{On-Farm Methane Measurement During Milking}

All cows used in this study were Holstein-Friesians from the Nottingham University Dairy Centre (Sutton Bonington, Leicestershire, UK; average annual milk yield 10,000 L/cow). For the on-farm parts of the study, cows were group housed under commercial conditions in a freestall barn and milked individually at automatic (robotic) milking stations in which cows presented themselves for milking, on average, 2.8 (SE 0.37) times per day. Milking stations used in experiment 1 (Fullwood Merlin; Fullwood Ltd., Ellesmere, UK) were replaced as part of an expansion and upgrade program for the facility and a different model of milking station (Lely Astronaut A3; Lely UK Ltd., St Neots, UK) was used in all subsequent experiments. Cows had ad libitum group access to partial mixed rations (PMR; Table 1) and concentrates were given to cows during milking. Concentrates were supplied by a commercial company (declared specification per kilogram as fed: ME, $12.2 \mathrm{MJ}$; CP, 16\%; NDF, 24\%; starch, 21\%; and fat, $6.2 \%$ ). Each cow's concentrate allocation, based on individual milk yield and number of milkings per day, was dispensed into the milking station's integral feed bin throughout each milking.

Methane concentrations were measured during milking using one infrared methane analyzer per milking station (Guardian Plus; Edinburgh Instruments Ltd., Livingston, UK) with a range of 0 to $10,000 \mathrm{mg} / \mathrm{kg}$. Air was drawn through the instrument by an integral pump between the gas inlet port and analyzer. Air was sampled continuously from the feed bins in the milking stations at $1 \mathrm{~L} / \mathrm{min}$ via an 8 -mm diameter polyethylene tube, approximately $3 \mathrm{~m}$ in length, connected to the 
Table 1. Formulation and composition of diet components fed to cows in experiments 1 and 3 (on farm), and experiments 2 and 4 (on farm and in respiration chambers)

\begin{tabular}{|c|c|c|c|}
\hline \multirow[b]{2}{*}{ Item } & \multicolumn{3}{|c|}{ Experiment } \\
\hline & 1 & $2,3\left(\right.$ Low $\left.\mathrm{CH}_{4}\right)$ & $3,4\left(\mathrm{High} \mathrm{CH}_{4}\right)$ \\
\hline \multicolumn{4}{|l|}{ Partial mixed ration } \\
\hline \multicolumn{4}{|l|}{ Ingredient $(\mathrm{g} / \mathrm{kg}$ of $\mathrm{DM})$} \\
\hline Grass silage & 322 & 132 & 316 \\
\hline Maize silage & 272 & 319 & 191 \\
\hline Whole crop silage & & 126 & 78 \\
\hline Lucerne hay & 99 & & \\
\hline Wheat straw & 21 & & \\
\hline Rape straw & & 50 & 30 \\
\hline Sugarbeet pulp & 44 & 96 & 113 \\
\hline Rapeseed meal & 82 & 132 & 78 \\
\hline Soybean meal & 55 & 84 & 50 \\
\hline Peas & & & 107 \\
\hline Fat supplement ${ }^{1}$ & 22 & 23 & 14 \\
\hline Molasses and urea $^{2}$ & 53 & & \\
\hline Minerals and vitamins ${ }^{3}$ & 30 & 37 & 23 \\
\hline \multicolumn{4}{|l|}{ Composition } \\
\hline DM $(g / k g)$ & 376 & 461 & 389 \\
\hline $\mathrm{ME}(\mathrm{MJ} / \mathrm{kg}$ of DM$)$ & 11.6 & 11.2 & 11.1 \\
\hline $\mathrm{CP}(\mathrm{g} / \mathrm{kg}$ of $\mathrm{DM})$ & 171 & 168 & 171 \\
\hline 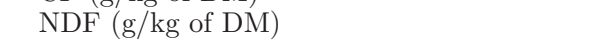 & 345 & 359 & 403 \\
\hline Starch $(\mathrm{g} / \mathrm{kg}$ of $\mathrm{DM})$ & 162 & 136 & 128 \\
\hline Oil $(\mathrm{g} / \mathrm{kg}$ of $\mathrm{DM})$ & 46 & 48 & 39 \\
\hline \multicolumn{4}{|l|}{ Concentrate $^{4}$ feeding during milking } \\
\hline Per cow $(\mathrm{kg} / \mathrm{d})$ & 2.0 & 1.5 & 1.5 \\
\hline Milk yield threshold for extra feed $(\mathrm{L} / \mathrm{d})$ & 29 & 23 & 23 \\
\hline Kilogram per liter milk yield above threshold & 0.29 & 0.16 & 0.16 \\
\hline
\end{tabular}

${ }^{1}$ Megalac (calcium salts of palm FA; Volac International Ltd., Royston, UK).

${ }^{2}$ Regumaize 44 (KW Alternative Feeds, Peterborough, UK).

${ }^{3}$ Bibby HiPhos (ABN Ltd., Peterborough, UK), containing calcium, 18\%; phosphorus, 10\%; magnesium, 5\%; salt, $17 \%$; copper, $2,000 \mathrm{mg} / \mathrm{kg}$; manganese, $5,000 \mathrm{mg} / \mathrm{kg}$; cobalt, $100 \mathrm{mg} / \mathrm{kg}$; zinc, $6,000 \mathrm{mg} / \mathrm{kg}$; iodine, 500 $\mathrm{mg} / \mathrm{kg}$; selenium, $25 \mathrm{mg} / \mathrm{kg}$; vitamin A, 400,000 IU $/ \mathrm{kg}$; vitamin $\mathrm{D}_{3}, 80,000 \mathrm{IU} / \mathrm{kg}$; and vitamin $\mathrm{E}, 1,000 \mathrm{mg} / \mathrm{kg}$. ${ }^{4}$ Manufacturer's declared specification per kilogram as fed: ME, $12.2 \mathrm{MJ}$; CP, 16\%; NDF, 24\%; starch, 21\%; and fat, $6.2 \%$.

gas inlet port of the analyzer. The exhaust port of the analyzer was vented into the air at least $3 \mathrm{~m}$ clear of any sampling point. An inline combined particle filter and water separator (Air-Pro IF-14; Flotec Industrial Ltd., Loughborough, UK) was fitted to the sample tube, approximately $50 \mathrm{~cm}$ from the analyzer inlet port. The inlet end of the sampling tube was positioned at the rear of the feed bin of the milking station. The design of the feed bins (Figure 1) differed between manufacturers, although both designs contained a trough approximately $50 \mathrm{~cm}$ wide $\times 50 \mathrm{~cm}$ long $\times 25$ $\mathrm{cm}$ deep into which concentrates were delivered via a chute approximately $8 \mathrm{~cm}$ in diameter; in experiment 1 , the feed bin was fully enclosed, except for the side that allowed cow access, and the concentrate delivery chute was behind a panel that left a slot $25 \mathrm{~cm}$ high $10 \mathrm{~cm}$ from the rear of the trough; in subsequent experiments, one of the vertical sides of the feed bin was not fully enclosed, although both sides extended to a height of $80 \mathrm{~cm}$ above the base of the trough, so a cow's head was enclosed within the feed bin approximately as far as its eyes while gathering a mouthful of concentrates, and approximately halfway from the nostrils to the eyes while resting or chewing concentrates. In experiment 1 , the sample tube was positioned $30 \mathrm{~cm}$ above the base, $15 \mathrm{~cm}$ from the side, and $10 \mathrm{~cm}$ from the rear of the feed trough, behind the panel; in subsequent experiments, the sample tube was positioned $50 \mathrm{~cm}$ above the base, $14 \mathrm{~cm}$ from the side, and $5 \mathrm{~cm}$ from the rear of the feed trough, adjacent to the concentrate dispenser chute and in line with the cow's nostrils. Sample pipes were checked daily for blockages. The high-methane alarm on each analyzer was set to a concentration of $1 \%$ methane, which was never reached in normal operation; the low-methane alarm was set to zero methane, which was triggered in the event of a loss of airflow due to pipe blockage.

Methane concentration was logged at 1 -sec intervals on data loggers (experiment 1: Lascar EL-USB-4; Lascar Electronics Ltd., Salisbury, UK; subsequent 

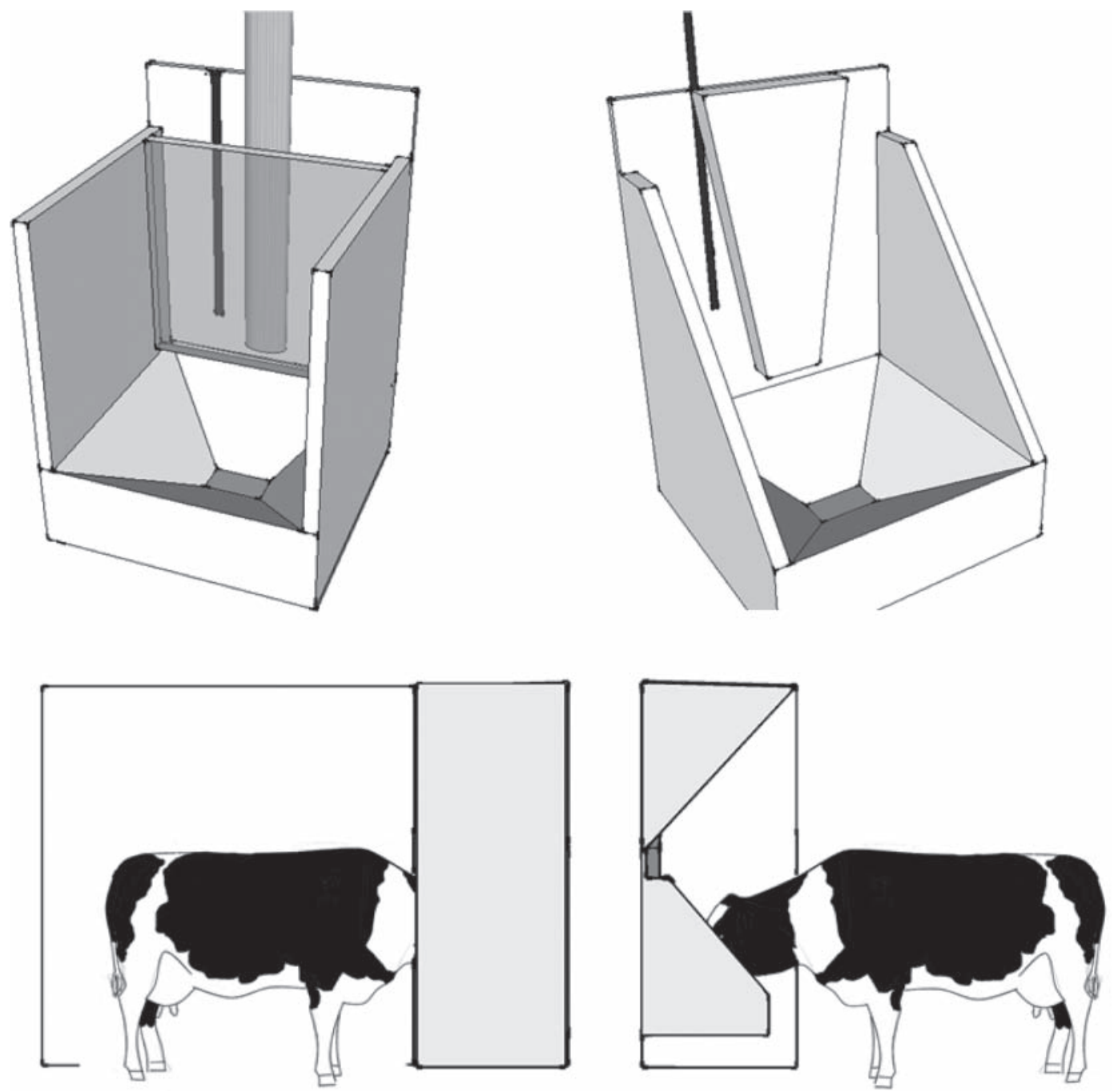

Figure 1. Diagrams of feed bins within automatic milking stations used in experiments 1 (left-hand side) and 2 (right-hand side). Top diagrams show positions of the sampling tube (solid black line); bottom diagrams show the position of a cow's head while eating concentrates; cows' heads were enclosed on both sides in experiment 1 , but only partially enclosed on one side in experiment 2.

experiments: Simex SRD-99; Simex Sp. z o.o., Gdańsk, Poland) and then visualized using logging software (Loggy Soft; Simex Sp. z o.o.). The capacity of the data loggers used in experiment 1 limited methane recording to periods of 8-h duration, but the data loggers used in subsequent experiments permitted continuous recording for up to $14 \mathrm{~d}$, although data were transferred to a personal computer every 1 or $2 \mathrm{~d}$, thus enabling perpetual recording. Before each monitoring period, the analyzer was calibrated using standard mixtures of methane in nitrogen $(0.0,0.25,0.50,0.75$, and $1.0 \%$ methane; Thames Restek UK Ltd., Saunderton, UK).

Methane concentrations measured in air sampled during milking followed a distinctive pattern of peaks (Figure 2), each consisting of a rapid rise followed by exponential decay, indicative of pulse-release of methane by eructation. Using a custom-designed program to identify and quantify peaks, raw data from the logger were transformed into values for peak height (maximum minus baseline methane concentration for each eructation) and integral of peak area (representing total methane release per eructation). Peaks with a height of less than $200 \mathrm{mg} / \mathrm{kg}$ above baseline were discarded. For each milking, mean peak height and integral were calculated, together with peak frequency (eructation rate). Milkings with fewer than 3 recorded eructations were eliminated from analysis because mean peak frequency could not be calculated reliably. An index of methane emission during each milking (MEIm) was calculated as the product of peak frequency and mean peak area. 


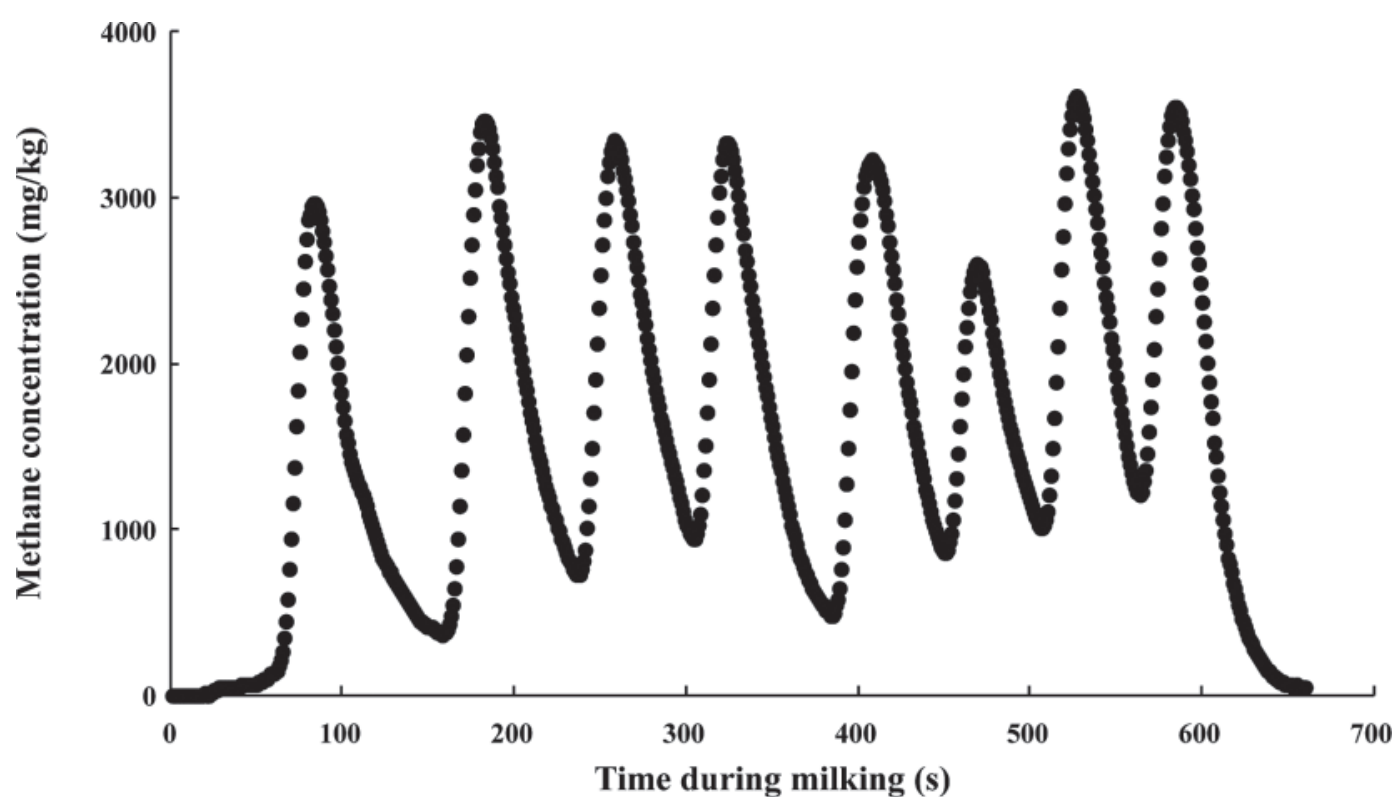

Figure 2. Changes in concentration of methane in air sampled from the feed bin of an automatic milking station during milking of one cow in experiment 1 . The $\mathrm{x}$-axis shows elapsed time since the cow entered the milking station for milking. Peaks in methane concentration correspond to eructations.

A factor for dilution of eructed air by ambient air was determined (on one occasion only, at the end of experiment 2) so that methane concentrations measured by the analyzer could be adjusted to estimate concentrations of methane in gas released by the cow. A fixed volume $(2.7 \mathrm{~L})$ of $1.0 \%$ methane in nitrogen was released instantaneously into the feed bin in the observed vicinity of cows' noses, although a cow was not present during the test. Release sites were at the base of the trough (to simulate a cow gathering concentrates), and at the center of the feed bin level with the sample tube (to simulate a cow resting or chewing concentrates). Methane release was replicated 6 times at each release site. The dilution factor was calculated as the mean ratio of methane concentrations in released and sampled gases. This dilution factor was used to convert MEIm to methane emission rate during milking (MERm).

In experiment 1, 82 cows (BW 454 to $786 \mathrm{~kg}$, milk yield 11 to $61 \mathrm{~L} / \mathrm{d}$, DIM 20 to 430 , and lactation number 1 to 4 ) were monitored during milking between the hours of 0800 and $1800 \mathrm{~h}$ on 4 separate days over a $9-\mathrm{d}$ period. Between 1 and 6 milkings, each containing 3 to 17 peaks, were recorded per cow.

In experiment 2, 12 cows (milk yield 20 to $40 \mathrm{~L} / \mathrm{d}$ ) were monitored at every milking for $10 \mathrm{~d}$ before transfer to respiration chambers at the Biosciences Research Unit. Approximately 30 milkings, each containing 4 to 15 peaks, were recorded per cow over the 10 -d on-farm monitoring period.

\section{Methane Measurement in Respiration Chambers}

In experiment 2, following the 10-d period of on-farm measurement of methane emissions during milking, cows were housed individually for 3 to $7 \mathrm{~d}$ in 1 of 2 respiration chambers to measure total daily methane emissions. In the respiration chambers, cows followed exactly the feeding regimen as that being used at the Dairy Centre. Cows were milked, fed and cleaned twice daily in the chambers at approximately 0745 and 1730 h.

Each chamber had a volume of $29.3 \mathrm{~m}^{3}$ with resinsealed concrete walls and floor, and a silicone-sealed polyvinyl chloride (PVC) ceiling. Doors at the front and rear of the chamber were fitted with rubber strips to render them airtight and an airlock system was installed to minimize loss of methane from the rooms during entry and exit by personnel.

Air-conditioned air was supplied to each chamber via a ceiling vent in front of the animal and extracted via a ceiling vent behind the animal at the rate of $10.2 \pm 0.05 \mathrm{~m}^{3} / \mathrm{min}$. Temperature and pressure were measured throughout the experiment (MSR145B51010 data logger; Omni Instruments Ltd., Dundee, $\mathrm{UK}$ ) and averaged $22 \pm 2.7^{\circ} \mathrm{C}$ and $100.7 \pm 1.61 \mathrm{kPa}$, respectively. Air flow rate was measured using air velocity sensors (model AV-DSP; Omni Instruments Ltd.) fitted in the air intake and exhaust ducts of each chamber. 
Methane concentrations were measured in air sampled from intake and exhaust ducts of each chamber using an infrared multigas analyzer with a range of 0 to $1,000 \mathrm{mg} / \mathrm{kg}$ (model 9000/345050; Signal Group Ltd., Camberley, UK). Air was sampled continuously for 2 min at each sampling point via 8-mm-i.d. PVC tubing placed in the central part of each duct. Samples were taken sequentially from chamber 1 intake, chamber 1 exhaust, chamber 2 intake, and chamber 2 exhaust. A settling time of $20 \mathrm{~s}$ was allowed after switching sampling points and then mean methane concentration was recorded for the remainder of each 2-min sampling period and logged at the end of each 8-min sampling cycle. The analyzer was calibrated automatically every $4 \mathrm{~h}$ using calibration gases for span $(800 \mathrm{mg} / \mathrm{kg}$ of methane in nitrogen; Air Products Plc, Crewe, UK) and zero (Technical Nitrogen; Air Products Plc). Visual observation of calibrations confirmed that the settling time of $20 \mathrm{~s}$ was sufficient for analyzer readings to stabilize after switching between span, zero, and sampling channels. Methane emissions by cows in chambers were calculated as the difference between inlet and outlet methane concentrations multiplied by volumetric air flow at the exhaust duct and corrected to standard temperature and pressure.

While cows were in the respiration chambers, methane concentrations in exhaled air were measured continuously using the same system as that used for on-farm monitoring of methane emissions during milking, but with a modification to methodology for air sampling. Samples of air released from the cow by exhalation and eructation were obtained via an 8-mm-diameter PVC tube attached to an 8-mm-diameter copper pipe placed in close proximity $(2-4 \mathrm{~cm})$ to the cow's nostrils and fixed to a halter. The other end of the tube was connected to the inlet port of an infrared methane analyzer of the same model as described for on-farm monitoring, which was sited outside the chamber. For comparison with chamber methane measurements, which were reported every $8 \mathrm{~min}$, methane peak data obtained from sampling eructated air were averaged over 8-min periods.

\section{Diet Effects on Methane Emissions During Milking}

A diet study (experiment 3) was conducted to examine the effects of 2 feeding regimens on MERm. A high-methane PMR was designed, which was predicted to generate higher methane emissions than the commercial (low-methane) PMR used in experiment 2 (Table 1). The high-methane PMR was based on the commercial PMR, with an increased proportion of grass silage plus peas and additional sugar beet pulp. These ingredients were predicted to induce higher methane emissions compared with other ingredients, based on reports of the Rowett Research Institute's Feedingstuffs Evaluation Unit (Giger-Reverdin and Sauvant, 2000). Each PMR was fed individually to 42 cows for a period of $14 \mathrm{~d}$ per treatment in a crossover design. Cows were paired according to milk yield in a preliminary period of 2-wk duration and assigned at random within pairs to 1 of the 2 PMR treatments in period 1; each cow was swapped to the other PMR treatment in period 2. Partial mixed ration ingredients were mixed by an automatic mixer system (Mullerup Smart Feeder; Skiold Mullerup A/S, Ullerslev, Denmark) and offered ad libitum to cows via Roughage Intake Control feeders (Fullwood Ltd.) with electronic recording of individual feed intake. Methane emission rate during milking was recorded throughout the $28 \mathrm{~d}$ of the study following the same procedures as for experiment 2 .

In experiment 4, the high-methane PMR was fed to 12 cows in respiration chambers for 3 to $7 \mathrm{~d}$ after a 14-d diet adaptation period, during which cows were housed in group pens and milked in individual standings. These were the same cows as used in experiment 2 to measure daily methane output in respiration chambers for the low-methane PMR, and the same procedures were followed for measuring daily methane output. Unfortunately, MERm could not be determined while the cows were milked in the standings during the diet adaptation period because the feed troughs were not enclosed.

\section{Statistical Analysis}

All statistical calculations were performed using the Genstat 14 statistical package (Lawes Agricultural Trust, Rothamsted, UK), except orthogonal regression, which was performed using Minitab 16 (Minitab Ltd., Coventry, UK).

In experiment 1 , the relationship between individual cow means for daily milk yield and MEIm was examined using regression with linear and quadratic terms. In experiment 2 , the relationship between individual cow means for MERm and subsequent daily methane emissions in respiration chambers was examined using orthogonal regression to allow for variations in measurements on both axes. Between- and within-cow variance components of on-farm and chamber measurements were obtained by fitting a linear mixed model to daily means with cow and day-within-cow as random effects, after adjusting for milk yield to account for different milking regimens on-farm and in chambers. Coefficients of variation were calculated from the cow (CV between cows) and the residual (CV within cows) variance components for MERm and chamber methane. The differ- 
Table 2. Characteristics of methane peaks recorded in 82 cows during milking under commercial conditions in experiment 1

\begin{tabular}{lcccc}
\hline Item & Mean & $\mathrm{SD}^{1}$ & Minimum & Maximum \\
\hline Milkings monitored per cow & 3.2 & 1.49 & 1 & 6 \\
Duration of milking (min) & 7.2 & 2.12 & 4.3 & 13.5 \\
Peaks per milking & 6.6 & 2.34 & 3 & 15.5 \\
Peak frequency (peaks/min) & 0.93 & 0.17 & 0.2 & 1.8 \\
Peak maximum methane concentration (g/L) & 1.2 & 0.32 & 0.55 & 1.99 \\
Peak area integral (mg of $\mathrm{CH}_{4} /$ peak) $^{2}$ (m) $\left./ \mathrm{min}\right)$ & 451 & 123 & 197 & 685 \\
Methane emission index during milking & 421 & 138 & 110 & 720 \\
\hline
\end{tabular}

${ }^{1}$ Standard deviation for between-cow variation.

${ }^{2}$ Product of peak frequency and area.

ence between variance components for the 2 data sets was used to indicate the relative variance that can be attributed to sampling regimen/occasion (Grainger et al., 2007).

In experiment 3 , responses to feeding regimen were examined using a linear mixed model with feeding regimen (PMR) as a fixed effect, and with cow and feeding period (1 or 2) as random effects. Mean data for each cow in each of the two 14-d feeding periods were used to ensure that the whole 14-d feeding period per cow was treated as one experimental unit when comparing feeding regimens. This model was used to analyze individual daily means for DMI, milk yield, BW, MERm, and MERm adjusted for DMI. Relationships between MERm and intakes of total DM, PMR DM, and concentrate DM were examined using a linear mixed model with feeding regimen (low or high methane), intake (continuous variate), and their interaction, as fixed

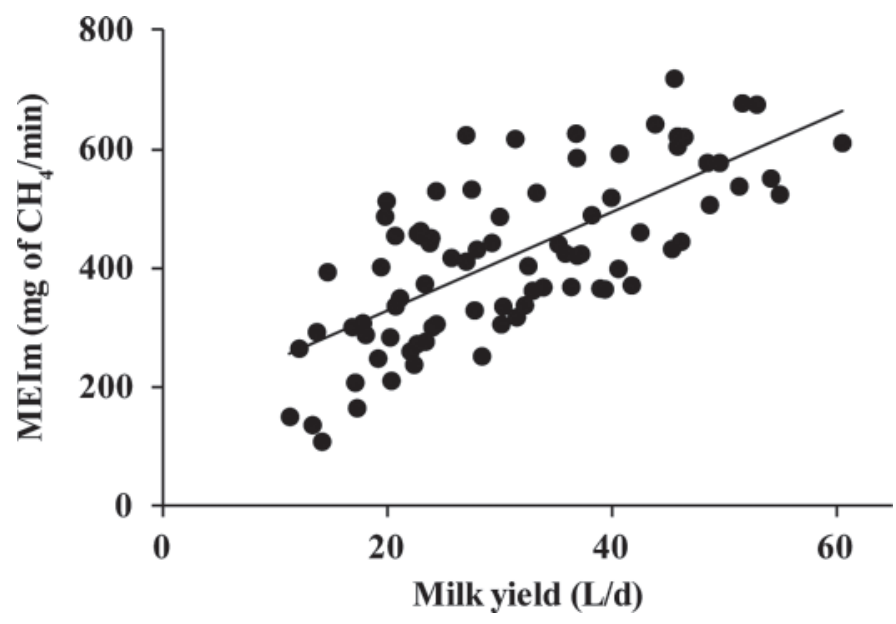

Figure 3. Relationship between daily milk yield and methane emission index measured during milking (MEIm) on farm in experiment 1. The MEIm was calculated from methane peaks (eructations) as the product of peak frequency and peak area, without correction for dilution with ambient air. Data points are individual means for 82 cows sampled during 1 to 6 milkings. The line shows the relationship $\left(\mathrm{R}^{2}=\right.$ $0.50, P<0.001)$. effects, and with cow and period (1 or 2) as random effects, where intake was either DMI fitted alone or PMR intake and concentrate intake fitted together. Repeatability of methane emissions within individual cows across diets was examined by orthogonal regression of mean MERm values obtained on both feeding regimens, and repeatability of cow ranking across diets was tested by calculating the Spearman rank correlation coefficient.

Combined data from respiration chamber measurements of mean daily methane output from each cow when fed the low (experiment 2) and high (experiment 4) methane PMR were analyzed as a linear mixed model, with PMR as a fixed effect and cow as a random effect. Relationships between methane output in respiration chambers (adjusted for DMI) for both PMR, and MERm measured in experiment 2 were examined using a linear mixed model with PMR, MERm, and their interaction, as fixed effects, and cow as a random effect.

\section{RESULTS}

\section{Experiment 1 (On-Farm Measurements)}

Considerable variation between cows was observed in pattern and magnitude of methane emissions during milking, as indicated by peak frequency, height, integral, and MEIm (Table 2). Between-cow coefficient of variation ranged from $17 \%$ for peak frequency to $33 \%$ for MEIm. Methane emission index was positively correlated with milk yield (Figure 3). The quadratic component of the relationship was not significant, but the linear relationship $\left(\mathrm{R}^{2}=0.50, P<0.001\right)$ was

$$
\begin{gathered}
\operatorname{MEIm}\left(\mathrm{mg} \text { of } \mathrm{CH}_{4} / \mathrm{min}\right)=164( \pm 30.5) \\
+8.26( \pm 0.92) \mathrm{MY}
\end{gathered}
$$

where MEIm is the methane emission index during milking and MY is the daily average milk yield per cow (L/d). 


\section{Experiment 2 (On-Farm Versus Chamber Measurements)}

The mean factor for dilution of eructed methane by ambient air, determined over 12 simulations, was 19.2 (SD 2.8) and did not vary $(P=0.953)$ between test positions within the feed bin. A linear relationship was found between MERm measured during milking over a 10 - $d$ period at the Dairy Centre and total daily methane output measured subsequently in respiration chambers for the same 12 cows on the same feeding regimen (Figure 4). The orthogonal-regression relationship between these parameters $\left(\mathrm{R}^{2}=0.79, P<0.001\right)$ was

$$
\begin{gathered}
\text { MEc }\left(\mathrm{g} \text { of } \mathrm{CH}_{4} / \mathrm{d}\right)=252( \pm 21.4) \\
+57.2( \pm 9.5) \mathrm{MERm},
\end{gathered}
$$

where MEc is the daily methane output measured in respiration chambers ( $\mathrm{g}$ of $\mathrm{CH}_{4} / \mathrm{d}$ ) and MERm is the average methane emission rate during milking ( $\mathrm{g}$ of $\mathrm{CH}_{4} / \mathrm{min}$ ) at the Dairy Centre.

When cows were in respiration chambers, methane emission rate measured using continuous sampling of exhaled and eructed air changed in parallel with methane output measured across chamber intake and exhaust ducts. When cows were eating, methane peaks were more frequent and showed higher methane concentrations, due to more eructations, leading to a higher methane emission rate. Methane output was elevated for 2 to $4 \mathrm{~h}$ after feeding as cows consumed their meals and digested rapidly fermentable material. Individual cows showed differences in pattern of feeding behavior, so changes in methane emission rate with time were not synchronized among cows. However, all cows showed consistently high emission rates while eating concentrates offered at milking. This is illustrated in Figure 5, where 8-min mean data for methane emission rate have been synchronized to time of morning and afternoon milking.

Across cows fed on the low-methane PMR, MERm measured during milking in chambers was correlated with MERm measured during milking at the Dairy Centre over the preceding $10-\mathrm{d}$ period $(\mathrm{r}=0.727, P=$ 0.007; Figure 6a); the orthogonal-regression relationship between these parameters was

$$
\begin{gathered}
\text { MERmc }\left(\mathrm{g} \text { of } \mathrm{CH}_{4} / \mathrm{min}\right)=-0.45( \pm 0.94) \\
+1.39( \pm 0.42) \text { MERm, }
\end{gathered}
$$

where MERmc is the average methane emission rate during milking in respiration chambers $\left(\mathrm{g}\right.$ of $\left.\mathrm{CH}_{4} / \mathrm{min}\right)$ and MERm is the average methane emission rate dur- ing milking ( $\mathrm{g}$ of $\mathrm{CH}_{4} / \mathrm{min}$ ) at the Dairy Centre. Overall means ( $\mathrm{g}$ of $\mathrm{CH}_{4} / \mathrm{min}, \pm \mathrm{SE}$ ) were $2.2( \pm 0.21)$ for MERm and $2.5( \pm 0.26)$ for MERmc. The MERmc was also correlated with mean MER measured throughout the $24 \mathrm{~h}$ in chambers $(\mathrm{r}=0.788, P=0.002$; Figure $6 \mathrm{~b})$; the orthogonal-regression relationship between these parameters was

$$
\begin{gathered}
\text { MERmc }\left(\mathrm{g} \text { of } \mathrm{CH}_{4} / \mathrm{min}\right)=-0.59( \pm 0.83) \\
+4.57( \pm 1.15) \text { MERc }
\end{gathered}
$$

where MERc is the average methane emission rate in respiration chambers ( $\mathrm{g}$ of $\mathrm{CH}_{4} / \mathrm{min}$ ).

The coefficient of variation within cow (day-to-day) was $14.4 \%$ for MERm measured on farm and $7.2 \%$ for methane emissions measured in chambers; the coefficient of variation within cow that can be attributed to this difference between on farm and chamber is $12.5 \%$. The coefficient of variation between cows was $28.6 \%$ for MERm measured on farm and $27.0 \%$ for methane emissions measured in chambers; the coefficient of variation between cows that can be attributed to this difference between on farm and chamber is $9.3 \%$.

\section{Experiment 3 (Diet Effects On Farm)}

When fed the high-methane PMR, cows exhibited lower DMI $(P<0.001)$ and lower milk yield $(P=$

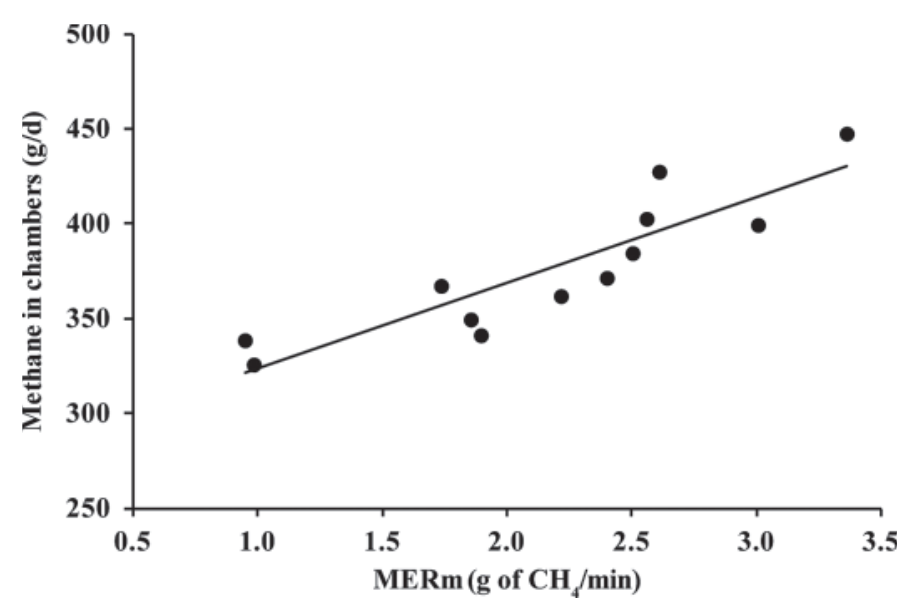

Figure 4. Relationship between methane emission rate measured during milking (MERm) on farm and total daily methane output measured for the same cows using respiration chambers in experiment 2. The MERm was calculated from methane peaks (eructations) as the product of peak frequency and peak area, adjusted for dilution. Data points are individual means for 12 cows sampled for MERm on farm at all milkings over a 10-d period and subsequently monitored in chambers for 3 to $7 \mathrm{~d}$. The line shows the relationship $\left(\mathrm{R}^{2}=0.79\right.$, $P<0.001)$. 


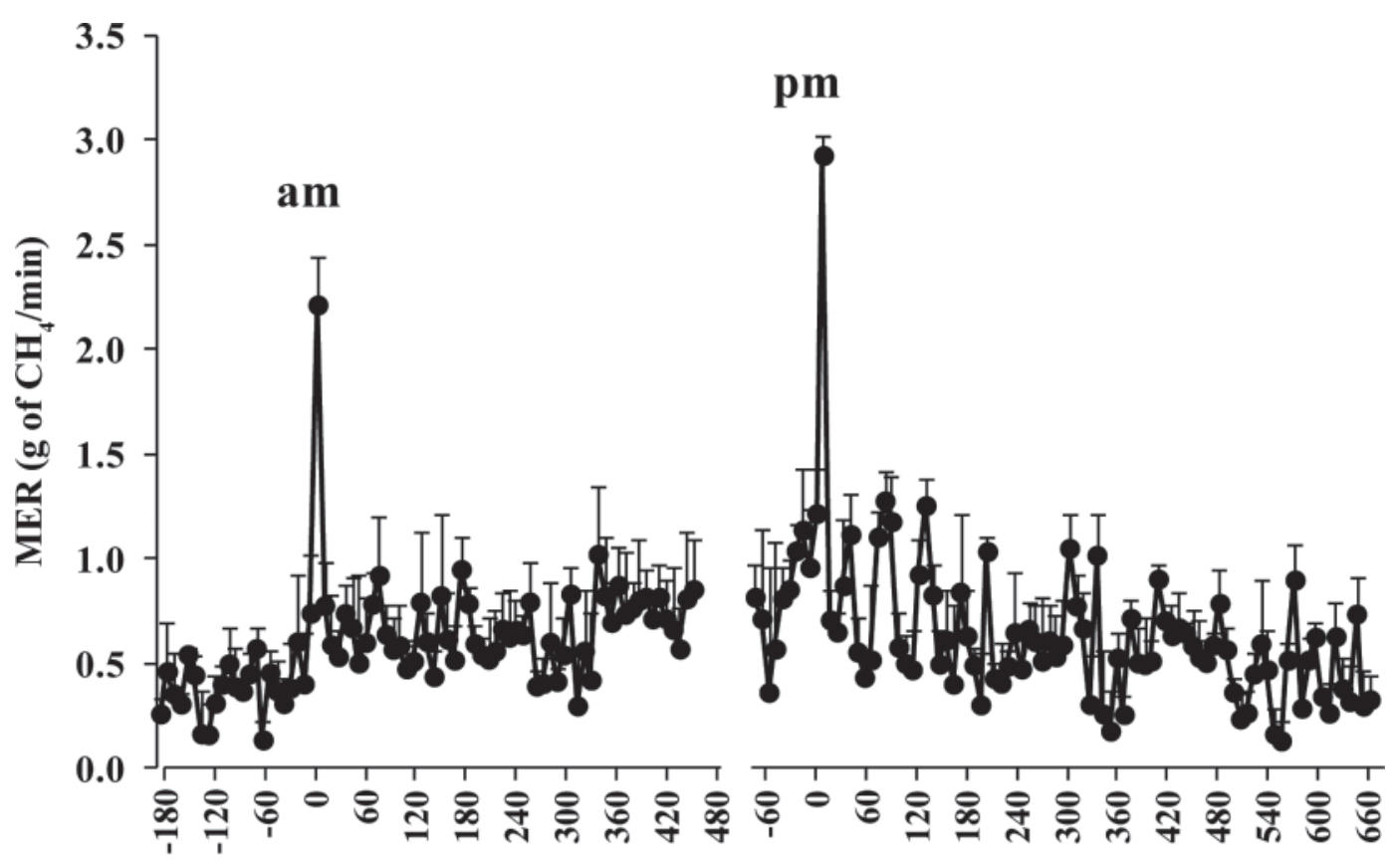

\section{Time relative to am and pm milkings (min)}

Figure 5. Mean methane emission rate (MER) over time measured by continuous sampling of exhaled and eructed air from 12 cows in respiration chambers. Data from individual cows were synchronized according to time of milking in morning (a.m.) or afternoon (p.m.). Note that for average milking times, 470 min after a.m. milking is equivalent to 76 min before p.m. milking.

0.034) than when fed the low-methane PMR (Table 3), but BW was not affected by feeding regimen. Methane emission rate during milking was significantly greater when cows were fed the high-methane PMR, expressed both as grams of $\mathrm{CH}_{4}$ per minute $(P=0.024)$ and as milligrams of $\mathrm{CH}_{4}$ per minute per kilogram of DMI $(P$ $<0.001)$.

Overall, MERm increased by $0.01( \pm 0.027) \mathrm{g}$ of $\mathrm{CH}_{4} /$ min for each kilogram increase in daily DMI $(P<$ 0.001), and no interaction was observed between PMR and DMI effects (Figure 7a). Responses to increasing intakes of PMR and concentrates were in opposite directions, however, and interactions with feeding regimen were significant $(P<0.05)$ in both cases. For PMR intake, MERm increased by $0.016( \pm 0.021) \mathrm{g}$ of $\mathrm{CH}_{4} /$ min for each kilogram increase in PMR DMI $(P$ $<0.001)$ when cows were fed the low-methane PMR, and by $0.037( \pm 0.029) \mathrm{g}$ of $\mathrm{CH}_{4} / \mathrm{min}$ for each kilogram increase in PMR DMI $(P<0.001)$ when cows were fed the high-methane PMR (Figure 7b). For concentrate intake, MERm decreased by $0.204( \pm 0.044) \mathrm{g}$ of $\mathrm{CH}_{4} /$ min for each kilogram increase in concentrate DMI $(P$ $=0.006)$ when cows were fed the low-methane PMR, and by $0.146( \pm 0.092) \mathrm{g}$ of $\mathrm{CH}_{4} / \mathrm{min}$ for each kilogram increase in concentrate DMI $(P=0.006)$ when cows were fed the high-methane PMR (Figure 7c).

A high degree of repeatability was observed for MERm measurements within individual cows when fed the high- and low-methane feeding regimens (Figure 8). The orthogonal regression relationship between means for MERm ( $\mathrm{g}$ of $\mathrm{CH}_{4} / \mathrm{min}$ ) within cows on the 2 feeding regimens was

high-methane MERm $=-0.15+1.22$ low-methane

$$
\operatorname{MERm}\left(\mathrm{R}^{2}=0.78 ; P<0.001\right) .
$$

The Spearman rank correlation coefficient for MERm of cows on low- versus high-methane feeding regimens was $0.86(P<0.001)$.

\section{Experiment 4 (Diet Effects in Chambers)}

When the high-methane PMR was fed to 12 cows in respiration chambers, the mean daily methane output was 395 (SE 12.7) g of $\mathrm{CH}_{4} / \mathrm{d}$, which was not different $(P=0.097)$ from mean daily methane output $[377$ (SE 10.7) $\mathrm{g}$ of $\mathrm{CH}_{4} / \mathrm{d}$ ] measured in respiration chambers 
Table 3. Effect of feeding regimens designed to alter methane emissions on DMI, milk yield, BW, and methane emission rate measured during milking in experiment 3

\begin{tabular}{|c|c|c|c|c|}
\hline Item & \multicolumn{2}{|c|}{ Feeding regimen } & $\mathrm{SED}^{1}$ & $P$-value \\
\hline DMI $(\mathrm{kg} / \mathrm{d})$ & 23.6 & 20.2 & 0.30 & $<0.001$ \\
\hline $\mathrm{BW}(\mathrm{kg})$ & 622 & 621 & 1.6 & 0.640 \\
\hline Methane emission rate $(\mathrm{g} / \mathrm{min})$ & 2.08 & 2.18 & 0.046 & 0.024 \\
\hline Methane emission rate (mg/min per kilogram of DMI) & 89 & 109 & 2.73 & $<0.001$ \\
\hline
\end{tabular}

${ }^{1}$ Standard error of the difference for comparing means.

for the same cows when fed the low-methane PMR in experiment 2. Dry matter intake was lower $(P<0.001)$, however, when cows were fed the high-methane PMR (13.6 versus 15.3, standard error of the difference 0.33 , $\mathrm{kg} / \mathrm{d})$. When expressed per unit DMI, daily methane output was 29.1 (SE 0.48) g of $\mathrm{CH}_{4} / \mathrm{kg}$ of DMI for
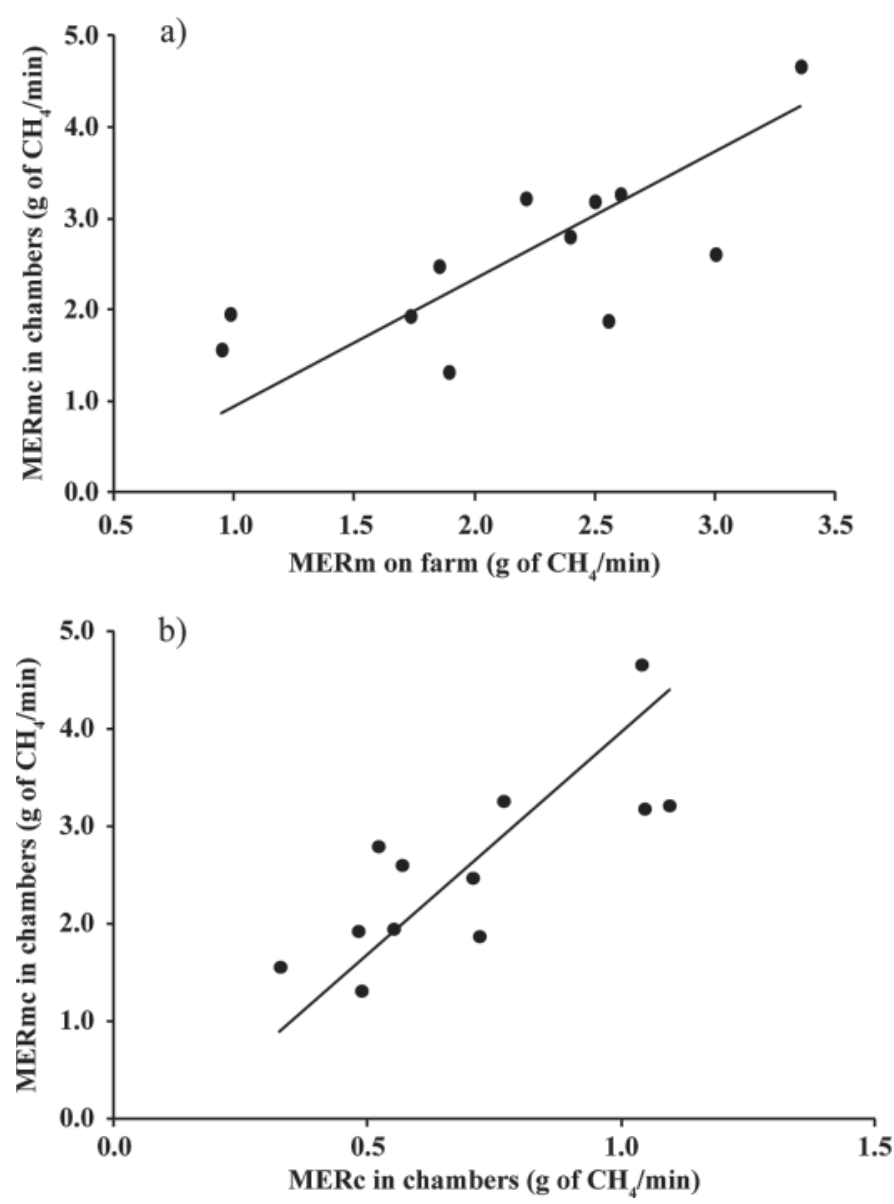

Figure 6. Relationships between methane emission rate during milking in respiration chambers (MERmc) and a) during milking on farm (MERm) or b) during the whole $24 \mathrm{~h}$ in respiration chambers (MERc). The lines are fitted by orthogonal regression. the high-methane PMR, which was greater $(P<0.001)$ than the mean daily methane output of 24.9 (SE 0.47) $\mathrm{g}$ of $\mathrm{CH}_{4} / \mathrm{kg}$ of DMI for the low-methane PMR. When expressed per unit gross energy intake, daily methane output was $7.60 \%$ (SE 0.25\%) for the high-methane PMR and $6.54 \%$ (SE 0.24\%) for the low methane PMR.

Despite a gap of $3 \mathrm{wk}$ between measuring MERm on-farm, when the cows were fed the low-methane $\mathrm{PMR}$, and measuring methane output in respiration chambers, when the cows were fed the high-methane PMR, a significant relationship $(P<0.001)$ was found between the two (Figure 9). The relationship between these parameters $\left(\mathrm{R}^{2}=0.74\right)$ was

$$
\begin{gathered}
\text { MEcDM }\left(\mathrm{g} \text { of } \mathrm{CH}_{4} / \mathrm{kg} \text { of DMI }\right)=21.4( \pm 1.5) \\
+3.6( \pm 0.67) \text { MERm, }
\end{gathered}
$$

where $\mathrm{MEcDM}$ is daily methane output measured in respiration chambers ( $\mathrm{g}$ of $\mathrm{CH}_{4} / \mathrm{kg}$ of DMI) when cows were fed the high-methane PMR, and MERm is the average methane emission rate during milking ( $\mathrm{g}$ of $\mathrm{CH}_{4} / \mathrm{min}$ ) when cows were fed the low-methane PMR at the Dairy Centre. The equivalent relationship for methane output in respiration chambers $\left(\mathrm{g}\right.$ of $\mathrm{CH}_{4} / \mathrm{kg}$ of DMI) when cows were fed the low-methane PMR in experiment $2\left(\mathrm{R}^{2}=0.77 ; P<0.001\right)$ was

$$
\begin{gathered}
\mathrm{MEcDM}\left(\mathrm{g} \text { of } \mathrm{CH}_{4} / \mathrm{kg} \text { of } \mathrm{DMI}\right)=16.8( \pm 1.5) \\
+3.7( \pm 0.64) \text { MERm. }
\end{gathered}
$$

When analyzed with a combined model, no significant interaction was found between feeding regimen and $\operatorname{MERm}(P=0.829)$, indicating that the slope of the relationship was the same for low- and highmethane PMR, but significant displacement between the lines occurred $(P=0.047)$, indicating consistently higher levels of chamber methane emissions at all levels of on-farm MERm values for the high-methane PMR. 


\section{DISCUSSION}

This study has confirmed that online sampling of air released by eructation during milking can provide useful information about variation among individual cows in methane emissions under on-farm conditions. The findings support our hypothesis that variation in eructation frequency and methane concentration in eructations is correlated with differences in daily methane emissions. Because the technique is noninvasive and relatively low cost, compared with other methods, repeated measures can be made on large numbers of individual cows to generate levels of replication as needed for statistical confidence. With further validation, the technique offers possibilities, therefore, for monitoring individual cows within herds to select animals with low emissions, to measure the success of mitigation strategies, and to provide estimates of uncertainty for inventory reports.

Enteric emissions of methane are driven by DMI (Grainger et al., 2007; Yan et al., 2010). This might explain some of the between-cow variation revealed in experiment 1, where MEIm was related to daily milk yield, which is correlated with DMI. Enteric methane emissions are also influenced by diet composition factors, including proportion of concentrates in the diet (Beauchemin et al., 2009). Following commercial practice, greater proportions of concentrates were fed to cows with higher milk yields in the current study. At any given level of milk yield, however, diet composition and predicted DMI did not vary among cows, yet MEIm varied by up to $40 \%$ of the mean. It is likely that this variation reflects variability in methane emissions that is independent of DMI. Variability among individuals has been reported from studies of cows in respiration chambers, and attempts are often made to control this by restricted feeding (Grainger et al., 2007). More importantly, experiment 2 showed good agreement between methane emissions data measured on farm (MERm) and total daily emissions measured subsequently in respiration chambers for the same cows. This relationship demonstrates that the method is quite sensitive because variation of 1 standard deviation in MERm was accompanied by a change of 1.1 standard deviation in daily methane output.

Grainger et al. (2007) used coefficients of variation within and between cows to provide an indication of the imprecision inherent the $\mathrm{SF}_{6}$ technique when applied concurrently with measurement of methane emissions from cows in respiration chambers. They reasoned that if the chamber measured real variation in methane emissions from the cow, and the $\mathrm{SF}_{6}$ technique measured variation in methane emissions plus additional error associated with the $\mathrm{SF}_{6}$ technique, then the additional imprecision due to the technique would be estimated
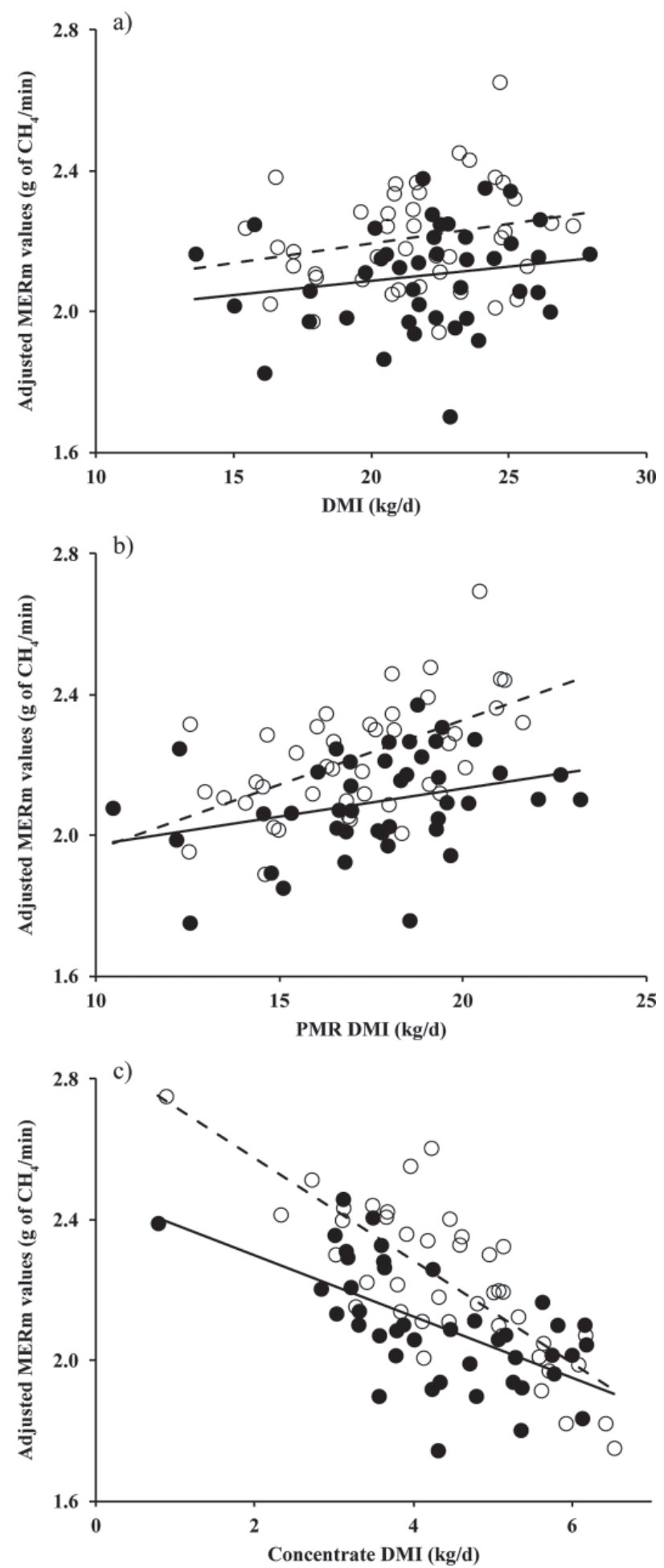

Figure 7. Relationships between methane emission rate during milking (MERm) and intakes of a) total DM, b) partial mixed ration (PMR) DM, and c) concentrate DM, for 42 individual cows on feeding regimens designed to induce low (closed circles, solid lines) or high (open circles, dashed lines) methane emissions. Values are model-predicted individual cow means over a 14-d period with MERm adjusted for effects of feeding period, and for effects of either concentrate DMI (b) or PMR DMI (c). 


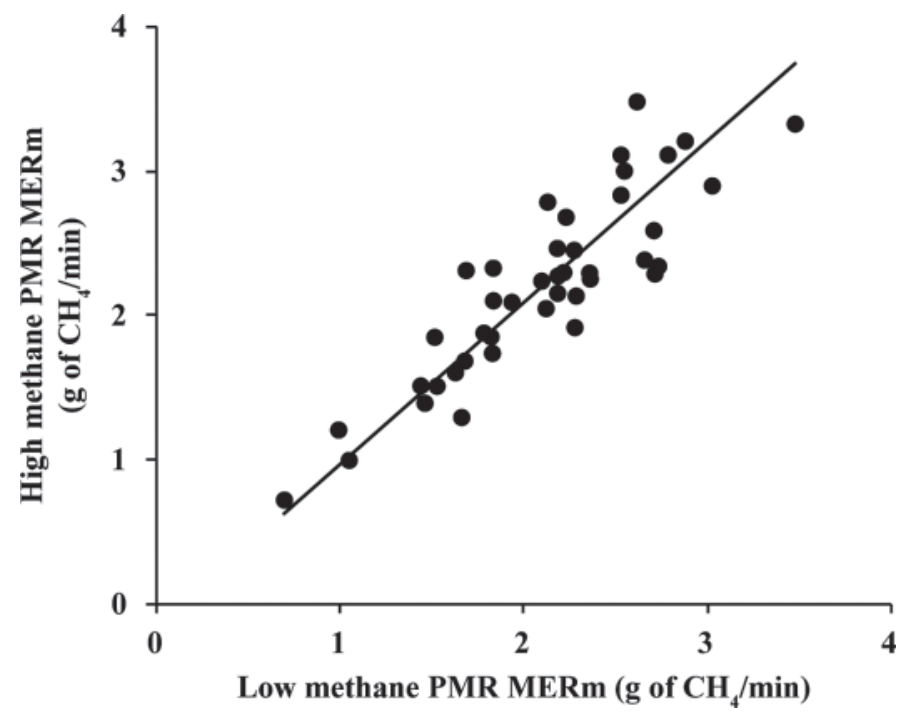

Figure 8. Methane emission rates during milking (MERm) on farm by individual cows on feeding regimens designed to induce low or high methane emissions. Data points are averages per cow over a 14-d feeding period on each feeding regimen.

by the difference in the corresponding $\mathrm{SF}_{6}$ and chamber components of variance. The logic of this reasoning breaks down somewhat when comparing variances for MERm and chamber measurements in the current study, because methane emissions were measured in different locations, under different milking regimens, and at different times. Nevertheless, comparison of variance components from on-farm and chamber measurements in experiment 2 provides useful insights into relative variations of the 2 measurements. Between cows, the coefficients of variation were of similar magnitude ( $28.8 \%$ on farm and $27 \%$ in chambers), and the implied contribution of the difference between techniques was $9.3 \%$. These results are similar to those of Grainger et al. (2007) who found between-cow coefficients of variation of $19.6 \%$ for the $\mathrm{SF}_{6}$ technique and $17.8 \%$ for respiration chambers, and estimated from their difference that the between-cow coefficient of variation for the $\mathrm{SF}_{6}$ technique itself was $8.2 \%$. Within cows, the on-farm coefficient of variation $(14.4 \%)$ was twice the chamber coefficient of variation (7.2\%), and the implied contribution of the difference between techniques was $12.5 \%$. Grainger et al. (2007) found within-cow coefficients of variation of $6.1 \%$ for the $\mathrm{SF}_{6}$ technique and $4.3 \%$ for respiration chambers, and estimated from the difference that the coefficient of variation for the $\mathrm{SF}_{6}$ technique itself was $4.3 \%$. Comparison of findings of the current study with those of Grainger et al. (2007) suggests that, compared with chamber measurements, on-farm measurements of methane emissions exhibit an increase in between-cow variability similar to that of the $\mathrm{SF}_{6}$ technique, but exhibit a greater difference in within-cow variability. Variability among and within cows can be accounted for more easily with on-farm estimation of methane emissions from MERm than with chambers or $\mathrm{SF}_{6}$ because repeated measurements can be made at little additional cost over prolonged periods of time. Furthermore, Clarke and Hannah (2007) demonstrated that an increase in coefficient of variation for a measurement technique may not lessen the precision of the result, providing more measurements are taken. Whereas Grainger et al. (2007) could attribute the increase in within-cow variability to the $\mathrm{SF}_{6}$ technique itself because both techniques were applied concurrently, the same conclusion cannot be drawn with certainty in the current study. It is possible that housing cows in chambers instead of freestalls, changing from free-choice to twice-daily milking at fixed times, and elapsed time could all decrease variation within cows. A possible alternative conclusion, therefore, is that measuring methane emissions by cows in respiration chambers does not reflect the true commercial situation. Variation between and within cows under onfarm conditions is quantified and explored further in a companion paper (Garnsworthy et al., 2012).

Although online monitoring was performed during milking, the fact that cows were eating during sampling is the important feature of the technique because ruminants exhibit eructations during periods of eating and rumination (Heywood and Wood, 1985). The technique has the potential to be applied, therefore, in any milking

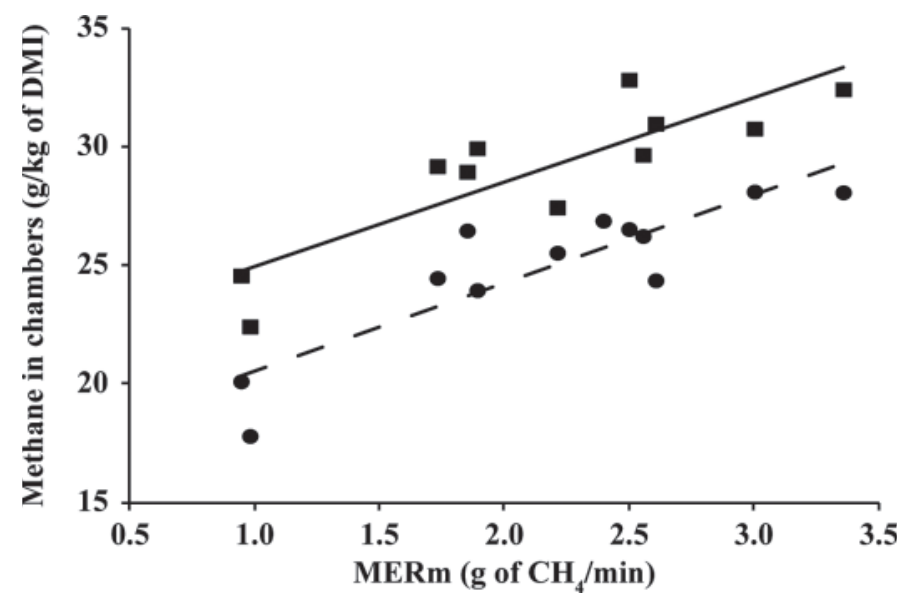

Figure 9. Relationships between methane emission rate measured during milking (MERm) on farm for 12 cows on the low-methane feeding regimen over a 10-d period, and total daily methane output (adjusted for DMI) measured in respiration chambers for the same cows on either the low-methane (circles, dashed line) or high-methane (squares, solid line) feeding regimens. Data points are individual cow means. 
system that includes concurrent feeding. Dilution factors used to adjust for dilution of eructed air by ambient air will vary among installations, although dilution did not vary between test positions within the feed bins used in experiment 2. This suggests that, provided a cow's nostrils are within the feed bin during eructation, it does not matter whether the cow is gathering concentrates, chewing, or resting. Eructations occurring when the cow's head is not in the feed bin, however, result in either no change or only small increases in methane concentration of sampled air; such small increases can be used to determine eructation frequency, but should be eliminated from calculation of mean methane released per eructation. Dilution factors allow conversion of methane concentrations in sampled air to methane emission rate by the cow, and the constant dilution rate used for all cows in experiment 2 ensures that variations between cows in MERm are related to the physiological parameters of eructation rate and methane released per eructation.

The online technique developed in this study does not account for methane released by flatulence because air is sampled only from the head end of the cow. Furthermore, only methane released by eructation is used to calculate MERm, thus discounting methane released in breath between eructations. We justify this approach because eructation has been reported as the major route for methane release in ruminants. Blaxter and Joyce (1963), using tracheostomized sheep in respiration chambers, estimated that only $17 \%$ of methane was produced from the lungs and the remaining $83 \%$ was produced by eructation. Similar estimates were obtained with sheep in the tracer study of Murray et al. (1976), where $83 \%$ of methane was excreted by eructation, $16 \%$ through the lungs, and 1\% through the anus. In the absence of reported evidence in dairy cows, we can only assume that dairy cows have similar proportioning between methane pathways as sheep.

Diurnal variation in methane output was observed when cows were in respiration chambers, in agreement with other studies (Johnson et al., 1994; Grainger et al., 2007). Continuous sampling from in front of the cow's nose while in chambers confirmed that changes in MER were reflected in changes in methane output. Importantly, the findings of this study confirmed that measurements made during milking and feeding, when both MER and methane output are high, were good indicators of variation among cows in total daily emissions. Further work is needed to investigate whether the relative times of milking and forage feeding would be important factors in on-farm monitoring. It should be noted that MER recorded in the respiration chambers during milking and feeding was approximately 8 times the daily average (Figure 5), so daily emissions cannot be calculated simply by multiplying MERm by the number of minutes in a day. Equations are needed, such as the one describing the relationship between MERm measured on-farm and daily methane output in chambers in experiment 2, for conversion of MERm values into daily emission values. Comparisons in experiment 4, of MERm measured for the low-methane feeding regimen with chamber measurements for both the high- and low-methane feeding regimens, suggest that one equation might be sufficient for comparing animals, but a suite of equations is required for different dietary scenarios.

The diet study (experiment 3) confirmed that the online monitoring system could detect a difference in methane output due to diet composition, and that the difference between PMR in MERm/ $\mathrm{kg}$ of DMI (20\%) was similar to the difference in methane output $(17 \%)$ measured in respiration chambers in experiments 2 and 4 , although it should be noted that respiration chamber measurements were confounded with time period. Importantly, in view of the between-cow variation observed in experiment 1, the experimental design used within-cow responses to test diet effects.

In the diet study (experiment 3), a positive relationship was found between MERm and total DMI, but responses were positive for PMR intake and negative for concentrate intake; this is in agreement with general observations of relationships between methane outputs and forage or concentrate intakes (Yates et al., 2000; Beauchemin et al. 2009). Attempts were made to describe the relationship in terms of nutrient intakes because different cows could have the same intake of NDF, starch, or FA while consuming different proportions of PMR and concentrates. None of these nutrients provided a significant addition to the model after allowing for effects of individual cows and feeding regimen. This is probably because only small differences existed between the PMR in concentration of these nutrients, and intake of each nutrient is confounded with DMI. For example, within cows, the lower average DMI of the high-methane PMR was offset by its slightly higher NDF concentration; within dietary treatments, cows with higher DMI would consume more of each nutrient, but the expected positive influence of NDF on methane would offset the negative influences of starch and FA. To establish relationships between MERm and nutrient intakes requires further studies in which nutrient composition is varied systematically. From the current study, conclusions have to be restricted to the fact that the online-monitoring technique can detect expected differences between feeding regimens designed to alter methane emissions. 
Availability of rapid, reliable, and cost-effective estimates of methane emissions by individual dairy cows under commercial conditions has implications for national methane inventories. Allowing for changes in animal numbers and diet composition, Garnsworthy (2004) calculated that total methane emissions per million liters of milk by cows producing $9,000 \mathrm{~L} / \mathrm{cow}$ per year was approximately $50 \%$ lower than methane emissions by cows producing $6,000 \mathrm{~L} /$ cow per year. In comparison, we can calculate that IPCC (2006) tier 1 methodology would predict a $33 \%$ decrease in emissions because it considers only the decrease in animal numbers; tier 2 methodology would predict a $15 \%$ decrease because, although net energy for maintenance is decreased by $33 \%$, net energy for lactation remains the same (to produce 1 million liters). Clearly, tier 3 methodology, using prediction equations, has the potential to increase the accuracy of national inventories and give due credit to mitigation strategies that decrease methane emissions without affecting animal numbers or gross energy intake. Accurate prediction equations are elusive, however; Ellis et al., (2010) tested 9 equations used for whole-farm prediction of methane emissions and found low prediction accuracy for all equations, which, they concluded, may introduce substantial error into inventories and lead to incorrect mitigation recommendations. On-farm monitoring has the potential to decrease uncertainty, or at least to quantify sources of variation, and to test the outcomes of mitigation strategies, by measuring indicators of emissions under commercial conditions.

\section{CONCLUSIONS}

On-farm monitoring of methane released by eructation during milking could provide a low-cost method for estimating variation in daily emissions by individual cows. Importantly, it offers a high level of replication as needed for statistical analysis. The technique correlates well with daily methane output measured subsequently for the same cows in respiration chambers and on the same feeding regimen. The technique also detected differences in methane emissions of cows on feeding regimens that induced high or low methane outputs in respiration chambers. The on-farm technique developed in this study identified a large degree of variation between animals. Acknowledging and identifying variability is required for national inventories and could have benefits for mitigation. Variability offers the potential for genetic selection of animals that have lower methane emissions per day or per unit of product; further study of the causes of variability between and within cows could suggest strategies by which overall methane emissions can be decreased.

\section{ACKNOWLEDGMENTS}

This work was funded by the Department for Environment, Food and Rural Affairs (London, UK; Project AC0219). We thank Adam Garnsworthy (TRIUMF, Vancouver, Canada) for development of data-handling software; Morag Hunter (University of Nottingham) for technical assistance; the staff of the University of Nottingham Dairy Centre and the Biosciences Research Unit for assistance with care of the animals; and Jeremy Colls, Holly Newman, and Kirsty Reid (all of University of Nottingham) for assistance with collection of initial data and prototype development for the on-farm technique.

\section{REFERENCES}

Beauchemin, K. A., T. A. McAllister, and S. M. McGinn. 2009. Dietary mitigation of enteric methane from cattle. CAB Rev.: Perspec. Agric. Vet. Sci. Nutr. Nat. Resour. 4:1-18.

Blaxter, K. L., and J. P. Joyce. 1963. The accuracy and ease with which measurements of respiratory metabolism can be made with tracheostomized sheep. Br. J. Nutr. 17:523-537.

Clarke, T., and M. C. Hannah. 2007. A simple statistical model to estimate precision of 300-day milk and fat production for dairy cows. Aust. J. Exp. Agric. 47:1095-1099.

Ellis, J. L., A. Bannink, J. France, E. Kebreab, and J. Dijkstra. 2010. Evaluation of enteric methane prediction equations for dairy cows used in whole farm models. Glob. Change Biol. 16:3246-3256.

FAO. 2010. Greenhouse Gas Emissions from the Dairy Sector: A Life Cycle Assessment. Food and Agriculture Organization of the United Nations, Rome, Italy.

Forster, P., V. Ramaswamy, P. Artaxo, T. Berntsen, R. Betts, D. W. Fahey, J. Haywood, J. Lean, D. C. Lowe, G. Myhre, J. Nganga, R. Prinn, G. Raga, M. Schulz, and R. Van Dorland. 2007. Changes in atmospheric constituents and in radiative forcing. Pages 129-234 in Climate Change 2007: The Physical Science Basis. Contribution of Working Group I to the Fourth Assessment Report of the Intergovernmental Panel on Climate Change. S. Solomon, D. Qin, M. Manning, Z. Chen, M. Marquis, K. B. Averyt, M. Tignor and H. L. Miller, ed. Cambridge University Press, Cambridge, UK and New York, NY.

Garnsworthy, P. C. 2004. The environmental impact of fertility in dairy cows: A modelling approach to predict methane and ammonia emissions. Anim. Feed Sci. Technol. 112:211-223.

Garnsworthy, P. C., J. Craigon, J. H. Hernandez-Medrano, and N. Saunders. 2012. Variation among individual dairy cows in methane measurements made on farm during milking. J. Dairy Sci. 95:3181-3189. http://dx.doi.org/10.3168/jds.2011-4606.

Giger-Reverdin, S., and D. Sauvant. 2000. Methane production in sheep in relation to concentrate feed composition from bibliographic data. Pages 43-46 in Proc 8th Seminar of the Sub-Network on Nutrition of the FAO-CIHEAM Inter-Regional Cooperative Research and Development Network on Sheep and Goats. INRA, Grignon, France.

Grainger, C., T. Clarke, S. M. McGinn, M. J. Auldist, K. A. Beauchemin, M. C. Hannah, G. C. Waghorn, H. Clark, and R. J. Eckard. 2007. Methane emissions from dairy cows measured using the sulfur hexafluoride $\left(\mathrm{SF}_{6}\right)$ tracer and chamber techniques. J. Dairy Sci. 90:2755-2766.

Griffith, D. W. T., G. R. Bryant, D. Hsu, and A. R. Reisinger. 2008. Methane emissions from free-ranging cattle: Comparison of tracer and integrated horizontal flux techniques. J. Environ. Qual. 37:582-591.

Heywood, L. H., and A. K. W. Wood. 1985. Thoracic esophageal motor activity during eructation in sheep. Q. J. Exp. Physiol. Cogn. Med. Sci. 70:603-614. 
IPCC (Intergovernmental Panel on Climate Change). 2006. 2006 IPCC Guidelines for National Greenhouse Gas Inventories. Prepared by the National Greenhouse Gas Inventories Programme. H. S. Eggleston, L. Buendia, K. Miwa, T. Ngara, and K. Tanabe, ed. Institute for Global Environmental Strategies (IGES), Hayama, Kanagawa, Japan.

Johnson, K., M. Huyler, H. Westberg, B. Lamb, and P. Zimmerman. 1994. Measurement of methane emissions from ruminant livestock using a sulfur hexafluoride tracer technique. Environ. Sci. Technol. 28:359-362.

Kinsman, R., F. D. Sauer, H. A. Jackson, and M. S. Wolynetz. 1995. Methane and carbon dioxide emissions from dairy cows in full lactation monitored over a six-month period. J. Dairy Sci. 78:2760 2766.

Laubach, J., and F. M. Kelliher. 2005. Methane emissions from dairy cows: Comparing open-path laser measurements to profile-based techniques. Agric. For. Meteorol. 135:340-345.

Lockyer, D. R. 1997. Methane emissions from grazing sheep and calves. Agric. Ecosyst. Environ. 66:11-18.

Murray, P. J., A. Moss, D. R. Lockyer, and S. C. Jarvis. 1999. A comparison of systems for measuring methane emissions from sheep. J. Agric. Sci. 133:439-444.
Murray, R. M., A. M. Bryant, and R. A. Leng. 1976. Rates of production of methane in the rumen and large intestine of sheep. Br. J. Nutr. 36:1-14.

Rotz, C. A., F. Montes, and D. S. Chianese. 2010. The carbon footprint of dairy production systems through partial life cycle assessment. J. Dairy Sci. 93:1266-1282.

Tremblay, F. J. B., and D. I. Massé. 2008. Instrumentation for precise quantification of methane emissions from dairy herds. Can. Biosyst. Eng. 50:21-28

Vergé, X. P. C., J. A. Dyer, R. L. Desjardins, and D. Worth. 2007. Greenhouse gas emissions from the Canadian dairy industry in 2001. Agric. Syst. 94:683-693.

Yan, T., C. S. Mayne, F. G. Gordon, M. G. Porter, R. E. Agnew, D. C. Patterson, C. P. Ferris, and D. J. Kilpatrick. 2010. Mitigation of enteric methane emissions through improving efficiency of energy utilization and productivity in lactating dairy cows. J. Dairy Sci. 93:2630-2638.

Yates, C. M., S. B. Cammell, J. France, and D. E. Beever. 2000 Prediction of methane emissions from dairy cows using multiple regression analysis. Page 94 in Proc. Br. Soc. Anim. Sci. 2000. Br. Soc. Anim. Sci., Penicuik, UK. 